\title{
L2 Motivation, Demographic Variables, and Chinese Proficiency among Adult Learners of Chinese
}

\author{
Meihua Liu \\ Tsinghua University
}

Correspondence concerning this article should be addressed to Meihua Liu, Department of Foreign Languages and Literatures, Tsinghua University, Beijing, 100084, PR China. E-mail: liumeihua@mail. tsinghua.edu.cn

\begin{abstract}
To validate Dörnyei'sL2 Motivational Self System (L2MSS) with data from learners of foreign languages other than English, the present quantitative study used the L2MSS framework to explore L2 motivation, demographic variables, and Chinese proficiency among adult learners of Chinese as a second language. A total of 83 international students studying in a Chinese university in Beijing answered the 54-item L2MSS questionnaire and a demographic questionnaire. Analyses of the data revealed the following main findings: a) the L2MSS scales were significantly related to one another and highly reliable, b) the ideal L2 self was significantly correlated with gender and the number of foreign languages learned (NFLL); integrativeness was significantly positively related to NFLL, c) the whole sample, as well as male and female participants, scored high on all L2MSS scales and had (great) motivation to study Chinese, d) female respondents held significantly more favorable perceptions of their ideal selves than their male peers, and e) the L2MSS had no predictive effect or interactive effect with demographic variables on students' Chinese proficiency. Nevertheless, length of stay in China and gender proved to be powerful positive predictors for students' Chinese proficiency. Evidently, the L2MSS scales are important dimensions of L2 motivation and closely related to second/foreign language learning. Understandably, it is necessary to continuously explore, understand, and enhance students' L2 motivation.
\end{abstract}

Keywords: L2 motivational self system, L2 motivation, demographic variable, Chinese proficiency, effect

\section{Introduction}

With a history of more than 50 years, research on second language (L2) motivation, an important factor in education at all levels, has been continuously developed and enriched both theoretically and empirically. The representative milestones of the development include the socio-psychological model that proposes the concepts of integrative and instrumental orientation (Gardner \& Lambert, 1972), the socio-educational model that expands the motivation construct to cover such factors as goals and confidence (Gardner, 1985; Gardner \& MacIntyre, 1992), and the L2 motivational self system (L2MSS) that links motivation and self images (Dörnyei, 2005,2009 b). Along with the development of theories on L2 motivation, a plethora of empirical studies on learners with diverse backgrounds in various second/foreign language (SL/FL) situations has been conducted (Csizér \& Dörnyei, 2005; Csizér \& Luka'cs, 2010; Dörnyei \& Al-Hoorie, 2017; Gardner, 1985; Liu, 2017, 2019) that pinpoint the important role of motivation in SL/FL learning. This interest in L2 motivation has never faded, and has actually surged, as revealed in Boo, Dörnyei, and Ryan's (2015) review of publications on L2 motivation from 2005 to 2014. The article also showed that, although there was a sharp increase in the number of studies within the L2MSS during that decade, more research is needed to further validate the theory. Moreover, as reviewed below, most research on L2 motivation centered on learners of English as a SL/FL, while research on learners of other languages as a SL/FL was far from adequate. Meanwhile, as noted in Csizér and Luka'cs (2010) and Henry (2010), a strong English-related ideal self might serve as a source of interference when learning another foreign language. Finally, China has been developing rapidly and interacting actively with the international community, and more and more people are studying Chinese as a second or foreign language. Nevertheless, research on these learners is inadequate (Liu, 2017). For these reasons, the present 
quantitative research, guided by Dörnyei's (2005, 2009b) L2MSS framework, aimed at exploring L2 motivation, demographic variables, and Chinese proficiency among adult international students registered in a university in Beijing.

\section{Literature Review}

Since the pioneering study on L2 motivation by Gardner and his associates (Gardner, 1985; Gardner \& Lambert, 1972; Gardner \& MacIntyre, 1992), L2 motivation has remained a flourishing topic in SL/FL teaching and research. No matter how L2 motivation theories develop, the fundamental concepts are integrative and instrumental orientation. Integrative orientation refers to an emotional identification with the target cultural group, positive attitudes toward the language community, and interest and desire for social interactions with the language community; and instrumental orientation involves obtaining pragmatic benefits from learning a SL/FL (Csizér \& Dörnyei, 2005; Gardner, 1985). Later, more concepts such as intrinsic motivation, extrinsic motivation, amotivation, and unconscious motivation were proposed (Dörnyei \& Al-Hoorie, 2017).

As the most promising L2 motivation theory in the recent decade, the L2MSS proposes viewing motivation as a function of the language learners' vision of their desired future language selves (Dörnyei \& Chan, 2013) and has three components: Ideal L2 self, ought-to L2 self, and L2 learning experience (Dörnyei, 2005, 2009b). Referring to the concept of possible selves proposed by Markus and Nurius (1986), Dörnyei (2005, 2009b) reconstructs L2 motivation as part of learners' self system, which shows how individuals think about themselves and their future. As discussed in Markus and Nurius (1986), possible selves represent individuals' ideas of what they might become, what they would like to become as well as what they are afraid of becoming and, thus, provide a conceptual link between self-concept and motivation. Corresponding to traditional integrative and internalized instrumental motives, the ideal L2 self involves the L2-specific facet of one's ideal self and serves as a powerful motivator to learn the L2 (Csizér \& Dörnyei, 2005; Dörnyei \& Chan, 2013). It is the "representation of all the attributes that a person would like to possess (e.g., hopes, aspirations, desires, or wishes)" (Csizér \& Dörnyei, 2005, p.616). Corresponding to Higgins' (1987) ought self and the more extrinsic types of instrumental motives, the ought-to L2 self refers to the "attributes that one believes one ought to possess (i.e., various duties, obligations, or responsibilities) and that therefore may bear little resemblance to one's own desires or wishes" (Csizér \& Dörnyei, 2005, p.617). The L2 learning experience involves situated and executive motives related to the immediate learning environment and experience (e.g., the impacts of teachers, curriculums, peers, and experiences of failure and success)(Csizér \& Dörnyei, 2005; Dörnyei, 2005, 2009b). According to the L2 motivational self system, there are three primary sources of motivation to learn an L2: “(a) the learners' internal desire to become an effective L2 user, (b) social pressures coming from the learner's environment to master the L2, and (c) the actual experience of being engaged in the L2 learning process" (Dörnyei \& Chan, 2013, p.439).

The L2MSS has been applied in various studies with a primary focus on English as the target language, assessed with questionnaires and/or interviews (Alshahrani, 2016; Chen, 2015; Csizér \& Dörnyei, 2005; Csizér \& Kormos, 2008; Csizér \& Luka'cs, 2010; Dörnyei \& Al-Hoorie, 2017; Dörnyei \& Csizér, 2002; Grant, Huang \& PasfieldNeofitou, 2018; Henry, 2017; Kormos \& Csizér, 2014; Liu, 2010; MacIntyre, Baker \& Sparling, 2017; Papi \& Abdollahzadeh, 2012; Pawlak, 2016a; Pawlak, 2016b; Ryan, 2009; Islam, Lamb \& Chambers, 2013; Yashima, 2009). These studies reveal that the ideal L2 self plays an important role in L2 motivation and that the L2MSS's components all correlate with learners' intended efforts to learn the target language and vary as learner characteristics and contexts change. For example, Kim's (2009) analyses of 974 surveys from Korean primary school students showed that motivation, visual style, imagination, the ideal L2 self, and motivated behavior were positively associated with each other. These findings were largely confirmed by Kim and Kim's (2014) study of elementary and junior high school students in Korea. Henry (2009, cited in Dörnyei \& Chan, 2013) found that the strength of the ideal L2 self increased significantly in teenage girls but decreased in boys over a period of four years in Sweden, resulting in a 'gender role intensification'. Papi's (2010) study of Iranian students showed that while the ought-to L2 self significantly made them more anxious, their ideal L2 self and L2 learning experience decreased their English anxiety. Cruz \& Al Shabibi (2019) examined the L2 motivational self system of four Omani college students by means of Dörnyei's (2009b) framework. Analyses of the interview data showed that the students associated ideal self with obtaining a (satisfactory) job, and that their complacency with their way of life in Oman and convenience in speaking their L1 hindered their motivation to 
learn English. Meanwhile, the study showed that learning experience did not generate motivation in the students to learn English and that people around them did not have a huge impact on the students' English learning.

Dörnyei and Chan (2013) examined whether learner characteristics were related to sensory and imagery aspects with indices of the strength of the learners' future L2 self-guides and how these variables were linked to learning achievements in English and Mandarin Chinese via both self-reporting and objective measures. Analyses of the data collected from 172 year 8 Chinese Cantonese speakers found that the learners' future selfguides were significantly related to their intended effort and actual grades, and that the ideal self was positively related to the criterion measures. Meanwhile, the study confirmed the importance of a broad imagery capacity in the development of learners' future self-identities. In addition, the study showed that the ideal L2 self associated with different languages formed distinct L2-specific visions, which offer a huge possibility for future research on the interaction of the ideal L2 self and the languages that learners are learning. Csizér and Luka'cs' (2010) survey study of 237 16/17-year-old learners of English and German revealed that students' ideal L2 self was the most significant component of predicting motivated learning behavior for both English and German as a first or second foreign language. Nevertheless, the study also found that the participants were fully positive only about English as a first FL but held both positive and negative attitudes toward English as a second FL and German either as a first FL or second FL. This finding, similar to Henry (2010), indicates that a strong Englishrelated ideal self might serve as a source of interference when learning another foreign language. This is surprising and deserves further research, especially on students learning foreign languages other than English.

Meanwhile, Boo et al.'s (2015) analysis of 416 empirical and conceptual papers and chapters on L2 motivation published between 2005 and 2014 demonstrated an overriding focus on the learning of English in L2 motivation research over that decade. The researcher, thus, claimed a clear need to study motivation to learn languages other than global English. Moreover, although there was a sharp increase in research within the framework of L2MSS, more research is needed to further validate the theory. As Chinese is being learned by more and more learners, additional research is needed to examine Chinese learning motivation beyond the small number of studies on this issue (Dörnyei \& Chan, 2013; Liu, 2017; Wen, 2011; Winke, 2013). Consequently, to validate Dörnyei's (2005, 2009b) L2 motivational self system (L2MSS) with data from learners of foreign languages other than English, the present research sought to explore L2 motivation, demographic variables, and Chinese proficiency among adult learners of Chinese as a second language registered in a university in Beijing. To achieve this purpose, the following research questions were proposed:

1) What were the profiles of the participants' $L 2$ motivation?

2) How was the participants' L2 motivation related to their demographic variables?

3) How did the participants' L2 motivation and demographic variables predict their proficiency in Chinese?

\section{Methodology}

\section{Context}

The present quantitative research was conducted in a research-oriented state-owned university in Beijing, which has enrolled increasingly more international students in various programs at both undergraduate and postgraduate levels in recent years. In this university, the language of instruction for most courses is Mandarin Chinese, with only a number of EMI (English as the medium of instruction) courses in some disciplines. Meanwhile, there are a wide range of opportunities for talks, seminars, forums, meetings, and exchanges in English with students and scholars from different parts of the world.

\section{Participants}

A total of 83 (50 male and 33 female) international students studying in a university in Beijing participated in the present study. With an average age of $24.72(\mathrm{SD}=3.57)$, they ranged from 18 to 39 years old and spoke 16 different native languages including English, Japanese, Russian, Korean, Nepalese, and Lao. Of these 
participants, eight were postgraduates and 75 were undergraduates, majoring in various disciplines like Chinese Medicine, Civil Engineering, Education, Finance, International Trade, Management, and Math. With an average of 30.43 ( $\mathrm{SD}=27.24$ ) and a mode of 36 months in China, the participants had been staying in China for varying lengths of time ranging from 1 month to 144 months. Likewise, with an average of $31.74(\mathrm{SD}=27.42)$ and a mode of 36 months of studying Chinese, they had been studying Chinese for varying periods as well, ranging from 2 to 156 months. Generally, they could speak zero to five foreign languages, with a mean of 2.59 (SD = 1.17) and Chinese was their first $(\mathrm{N}=10)$, second $(\mathrm{N}=36)$, third $(\mathrm{N}=30)$, fourth $(\mathrm{N}=4)$, or fifth $(\mathrm{N}=3)$ foreign language. On average, they spent 1 to 10 hours and a mean of $4.08(\mathrm{SD}=2.97)$ (mode $=2)$ hours using Chinese (speaking, listening, reading, and writing) each day.

\section{Assessments and measures}

The data in the present research was collected via a demographic questionnaire and the L2MSS questionnaire, as detailed below.

\section{The demographic questionnaire}

The participants were required to respond to questions related to their demographic information such as gender, age, native language, area of study, education level, length of stay in China, length of studying Chinese, number of foreign languages learned, and average hours spent using Chinese per day.

\section{Proficiency in Chinese}

Mainly because the students majored in various disciplines and varied in Chinese proficiency, it was difficult to administer the same standardized Chinese proficiency test simultaneously. The participants were thus asked to self-rate their proficiency in Chinese on a scale of 1 (the lowest) to 7 (native-like).

\section{The L2 motivational self system (L2MSS) questionnaire}

The L2MSS questionnaire used in the present study was adapted from that used by Taguchi, Magid and Papi (2009) and Kormos and Csizér (2014).The original questionnaire had 56 items, covering eight dimensions. To better suit the present research, two modifications were made to the original questionnaire: 1) the word "English" was changed to "Chinese" in all items, and 2) two items were deleted: "I study English not because I want to emigrate abroad but because it is an international lingua franca" and "I study English because I want certificates". The resultant questionnaire had 54 items (Cronbach alpha $a=.975$ ) and covered eight dimensions:

1) criterion measures ( 6 items) $(a=.891)$, which assess the learners' intended efforts toward learning Chinese, e.g., "I think I am doing my best to learn Chinese."

2) ideal L2 self ( 7 items) $(a=.906)$, which concerns students' view of themselves as successful Chinese speakers, e.g. "I often imagine myself speaking Chinese as if I were a native speaker of Chinese."

3) ought-to L2 self (7 items) $(a=.894)$, which measures important others' view of how important learning Chinese is in order to avoid negative outcomes, e.g. "I study Chinese because close friends of mine think it is important."

4) L2 learning experience (5 items) $(a=.905)$, which involves what extent respondents like Chinese learning, e.g. "I like the atmosphere of Chinese classes."

5) instrumentality-promotion (8 items) $(a=.934)$, which measures respondents' ideal image of being professionally successful, e.g. "Learning Chinese can be important to me because I think I'll need it for further studies."

6) integrativeness (9 items) $(a=.921)$, which assesses students' positive attitudes toward Chinese, its culture and native speakers of Chinese, e.g., "I like the music of Chinese-speaking countries."

7) international posture (7 items) $(a=.872)$, which measures respondents' tendency to relate themselves to the global community of Chinese, e.g. "I want to make friends with international students or foreigners in China."

8) instrumentality-prevention (5 items) $(a=.902)$, which explores the regulation of duties and obligations for learning Chinese, e.g. "Studying Chinese is necessary for me because I don't want to get a poor score on Chinese proficiency tests."

All the items were placed on a six-point Likert scale ranging from 'Strongly Disagree' to 'Strongly Agree', with values 1 to 6 assigned to each of the descriptors respectively. 


\section{Data collection and analyses}

Since the L2MSS questionnaire has proved to be valid in the current literature, it was piloted with three international students studying in China to see whether any modifications were needed. Based on the results, two items were deleted and others were reworded. Participation in the main study was voluntary, the participants were free to reveal their names and filled in the questionnaires and a consent form online. The data obtained were computer-coded via SPSS20. The overall Cronbach Alpha value was computed to show the reliability of each L2MSS scale. Then, correlation analyses (Pearson) were conducted to identify the relationships among the L2MSS scales and between the L2MSS scales and demographic variables. Independent samples t-test results were run to explore the significance of gender differences in L2 motivation. Finally, regression analyses were run to reveal the predictive effects of L2MSS on students' proficiency in Chinese and the interactive effects of L2MSS and demographic variables on the latter.

\section{Results}

\section{Correlations within the L2MSS scales}

As seen in Table 1, correlation analyses showed that the L2MSS scales were significantly positively related to one another with a large effect size $(r=.375 \sim .895, \mathrm{p} \leqslant .001)$. For example, the participants who had a more positive image of ideal L2 self tended to have a more positive image of ought-to L2 self.

Of the coefficients, those between IL2S (ideal L2 self) $(r=.435 \sim .825, \mathrm{p} \leqslant .001)$ and other scales and those between L2LE (L2 learning experience) and other scales $(r=.375 \sim .838, \mathrm{p} \leqslant .001)$ were fairly high. The second important finding was the high correlations between IPro (instrumentality-promotion) $(r=.544 \sim .895, \mathrm{p} \leqslant .001$ ), Int (integrativeness) $(r=.521 \sim .895, \mathrm{p} \leqslant .001)$, InP (international posture) $(r=.704 \sim .838, \mathrm{p} \leqslant .001)$ and other scales. In addition, although positively significantly related to other variables, OL2S (ought-to L2 self) had the lowest coefficient with L2LE $(r=.375 \sim .636, \mathrm{p} \leqslant .001)$ but the highest coefficient with IPre (instrumentalityprevention) $(r=.636, \mathrm{p} \leqslant .001)$.

Table 1

Correlations between L2MSS Scales $(N=83)$

\begin{tabular}{|c|c|c|c|c|c|c|c|}
\hline & IL2S & OL2S & L2LE & IPro & Int & InP & IPre \\
\hline L2CM & $.803 * *$ & $.447^{* * * *}$ & $.818^{* * *}$ & $.675^{* * *}$ & $.716^{* * *}$ & $.765^{* * *}$ & $.482^{* * *}$ \\
\hline IL2S & 1 & $.459^{* * * *}$ & $.761^{* * *}$ & $.825^{* * *}$ & $.806 * *$ & $.754^{* * *}$ & $.435 \% *$ \\
\hline OL2S & & 1 & .375 *** & $.544^{* * *}$ & $.521^{* * *}$ & $.548 * *$ & $.636 \% *$ \\
\hline L2LE & & & 1 & $.784^{* * *}$ & $.815^{* * *}$ & $.838 * *$ & $.494 * *$ \\
\hline IPro & & & & 1 & $.895 * *$ & $.819 * *$ & $.609 * *$ \\
\hline Int & & & & & 1 & $.825 \% *$ & $.537 * *$ \\
\hline InP & & & & & & 1 & $.704^{* * *}$ \\
\hline IPre & & & & & & & 1 \\
\hline
\end{tabular}

Notes: L2CM = criterion measures; IL2S = ideal L2 self; OL2S = ought-to L2 self

L2LE = L2 learning experience; IPro = instrumentality-promotion

Int = integrativeness; InP = international posture

IPre = instrumentality-prevention; $\quad * *=p \leqslant .001$

coefficient of determination: small $=r \leqslant 0.1 ;$ medium $=r=0.3 ;$ large $=r \geqslant 0.5($ Cohen, 1988)

\section{Correlations between L2MSS Scales and demographic variables}

As reported in Table 2, correlation analyses showed that among all the correlations, only the number of foreign languages learned was significantly positively related to IL2S (ideal L2 self) $(r=.290, \mathrm{p}=.008$ ) and Int (integrativeness) $(r=.233, \mathrm{p}=.035)$. Alternatively, the more foreign languages a respondent learned, the better perceived ideal L2 self they had for themselves, and the more integratively motivated they were to study Chinese. Meanwhile, IL2S (ideal L2 self) $(r=.301, \mathrm{p}=.006)$ was significantly correlated with gender, with a medium effect size, indicating that female participants had more positive perceptions of their ideal L2 selves. 
Table 2

Correlations between L2MSS Scales and Demographic Variables $(N=83)$

\begin{tabular}{lccccccc}
\hline & Gender & Age & SCP & LSC & LSCH & NFLL & HSUC \\
\hline L2CM & .174 & -.027 & -.175 & -.203 & -.129 & .129 & -.003 \\
IL2S & $.301^{* * *}$ & -.075 & -.032 & -.049 & .046 & $.290^{* * *}$ & .067 \\
OL2S & -.146 & .200 & -.116 & -.199 & -.159 & .058 & -.076 \\
L2LE & .202 & -.126 & -.056 & -.110 & .011 & .118 & .092 \\
IPro & .158 & -.077 & .099 & .059 & .140 & .197 & .084 \\
Int & .196 & -.005 & .105 & -.049 & .043 & $.233^{*}$ & .028 \\
InP & .152 & -.073 & -.075 & -.088 & -.013 & .198 & .031 \\
IPre & -.008 & .114 & .079 & .036 & .074 & .086 & .023 \\
\hline
\end{tabular}

Notes: SCP = self-rated Chinese proficiency; LSC= length of stay in China;

LSCH = length of studying Chinese; NFLL = the number of foreign languages learned; HSUC = hours spent in using Chinese per day; $* * *=p \leqslant$ $.01 ; * \mathrm{p} \leqslant .05$

For each block, the first number is the coefficient and the second is probability level, separated by a hyphen.

coefficient of determination: small $=r \leqslant 0.1 ;$ medium $=r=0.3$; large $=r \geqslant 0.5$ (Cohen, 1988)

\section{L2 motivation level}

As summarized in Table 3, except that OL2S (ought-to L2 self) had a mean of 3.64, all the other L2MSS scales scored more than 4 (mean $=4.07 \sim 4.49$ ), far above the scale midpoint 3.5. Namely, the participants made good or even great efforts to study Chinese, held (fairly) high perception of their ideal and ought-to selves, had positive attitudes toward their L2 learning experience, were highly instrumentally and integratively motivated, and had a great motivation of having an international posture.

Table 3

Means and Standard Deviations of L2MSS Scales

\begin{tabular}{|c|c|c|c|c|c|c|c|c|c|}
\hline & \multicolumn{2}{|c|}{$\begin{array}{l}\text { The whole sample } \\
\qquad(\mathrm{N}=83)\end{array}$} & \multicolumn{2}{|c|}{ Male $(\mathrm{N}=50)$} & \multicolumn{2}{|c|}{ Female $(\mathrm{N}=33)$} & \multicolumn{3}{|c|}{ t-test results } \\
\hline & M & SD & M & SD & $\mathbf{M}$ & SD & $\mathbf{t}$ & $\mathbf{p}$ & Cohen'd \\
\hline L2LM & 4.25 & 1.07 & 4.10 & 1.17 & 4.47 & .86 & -1.59 & .116 & / \\
\hline IL2S & 4.36 & .11 & 4.09 & 1.19 & 4.77 & .85 & $-2.84^{* * *}$ & .006 & 0.66 \\
\hline OL2S & 3.64 & 1.20 & 3.78 & 1.11 & 3.43 & 1.31 & 1.32 & .190 & I \\
\hline L2LE & 4.47 & 1.14 & 4.29 & 1.32 & 4.76 & .74 & -1.86 & .067 & / \\
\hline IPro & 4.36 & 1.20 & 4.21 & 1.32 & 4.59 & .97 & -1.44 & .153 & / \\
\hline Int & 4.49 & 1.06 & 4.32 & 1.19 & 4.74 & .78 & -1.78 & .078 & / \\
\hline $\mathrm{InP}$ & 4.36 & 1.07 & 4.23 & 1.26 & 4.56 & .66 & -1.37 & .174 & / \\
\hline IPre & 4.07 & 1.29 & 4.08 & 1.29 & 4.05 & 1.31 & .074 & .941 & / \\
\hline
\end{tabular}

The same pattern was observed with male and female respondents respectively. Moreover, female respondents scored higher on L2LM, IL2S, L2LE, IPro, Int, and InP but lower on OL2S and IPre than their male counterparts. However, a statistically significant difference was observed only in IL2S, as evidenced by the independent samples t-test results reported in Table 3.

\section{Regression analyses}

Regression analyses (stepwise) were run to explore the predicting effect of the L2MSS on the participants' Chinese proficiency, with self-rated proficiency in Chinese being the dependent variable and L2MSS scales being independent variables. This, however, produced no models, suggesting that the L2MSS scales had no predictive effect on the students' Chinese proficiency.

Then, regression analyses (stepwise) were run again, with self-rated proficiency in Chinese being the dependent variable and demographic variables (i.e., gender, age, length of stay in China, length of studying Chinese, the number of foreign languages learned, and average hours spent using Chinese per day) being independent 
variables. This produced one model with an $\mathrm{R}$ square change of $.277(\mathrm{p}=.000)$. The results are reported in Table 4 , which reveals that LSC (length of stay in China) $\left(\beta=.527, \mathrm{t}=5.366, \mathrm{f}^{2}=0.38\right.$ ) was a powerful positive predictor of students' proficiency in Chinese, with a large effect size.

Table 4

Multiple Regression Coefficients and Significance of Predictors for Chinese Proficiency

\begin{tabular}{lcccccc}
\hline Chinese proficiency & $\boldsymbol{\beta}$ & $\mathbf{t}$ & $\mathbf{p}$ & VIF & Cohen's f $^{2}$ \\
\hline LSC & .527 & 5.366 & .000 & 1.000 & 0.38 &
\end{tabular}

Notes: $* *=p \leqslant .01 ; *=p \leqslant .05$

effect size of Cohen's $\mathrm{f}^{2}:$ small $=\mathrm{f}^{2} \leqslant .02 ;$ medium $=\mathrm{f}^{2}=.15 ; \quad$ large $=\mathrm{f}^{2} \geqslant .35$ (Cohen, 1988)

To test the interactive effect of L2MSS scales and demographic variables on proficiency in Chinese, regression analyses (stepwise) were run again, with self-rated proficiency in Chinese being the dependent variable and L2MSS scales and demographic variables (i.e., gender, age, length of stay in China, length of studying Chinese, the number of foreign languages learned, and average hours spent using Chinese per day) being independent variables. This produced two models with an R square change of $.305(\mathrm{p}=.000)$ for model 1 (LSC) and $.044(\mathrm{p}=$ .031) for model 2 (LSC, gender). The results are reported in Table 5, which shows that LSC (length of stay in China) $\left(\beta=.562, \mathrm{t}=5.865, \mathrm{f}^{2}=0.44\right)$ and gender $\left(\beta=.211, \mathrm{t}=2.2, \mathrm{f}^{2}=0.05\right)$ were powerful positive predictors of students' proficiency in Chinese, with a large and small effect size respectively.

Table 5

Multiple Regression Coefficients and Significance of Predictors for Chinese Proficiency

\begin{tabular}{lccccc}
\hline Chinese proficiency & $\boldsymbol{\beta}$ & $\mathbf{t}$ & $\mathbf{p}$ & VIF & Cohen's $^{2}$ \\
\hline LSC & .562 & 5.865 & .000 & 1.002 & 0.44 \\
Gender & .211 & 2.2 & .031 & 1.002 & 0.05 \\
\hline
\end{tabular}

Notes: $* * * 0 \leqslant .01 ; *=p \leqslant .05$

effect size of Cohen's $\mathrm{f}^{2}$ : small $=\mathrm{f}^{2} \leqslant .02 ;$ medium $=\mathrm{f}^{2}=.15 ; \quad$ large $=\mathrm{f}^{2} \geqslant .35$ (Cohen, 1988)

\section{Discussion}

\section{Correlations within and between L2MSS Scales and demographic variables}

The present study revealed that the L2MSS scales were significantly correlated with one another, as found in many current studies (Csizér \& Luka'cs, 2010; Dörnyei \& Al-Hoorie, 2017; Dörnyei \& Chan, 2013; Dörnyei \& Csizér, 2002; Kim, 2009; Islam et al., 2013). This meant that a respondent who scored high on one L2MSS scale tended to score high on other L2MSS scales. Coupled with high reliability scores, this suggested that all eight components are important dimensions of L2 motivation and play important roles in SL/FL learning (Dörnyei, 2005, 2009b).

Meanwhile, the high coefficients between IL2S (ideal L2 self) and other scales and those between L2LE (L2 learning experience) and other scales (see Table 1) supported the original assumption made by Dörnyei (2005, $2009 \mathrm{~b}$ ) that possible selves and L2 learning experience are core components of L2 motivation and second language acquisition. Likewise, the high correlations between IPro (instrumentality-promotion), Int (integrativeness), InP (international posture), and other scales further proved that instrumental and integrative motivation are crucial dimensions of second language motivation (Dörnyei, 1994; Gardner, 1985; Gardner \& MacIntyre, 1992; Tremblay\& Gardner, 1995). This finding, as found in Liu (2016), also indicated that international posture is an important component of L2 motivation, highly related to SL/FL learning. This might be because the participants in the present study were international students studying in China, expecting to gain a global view by studying abroad. Different from that in Rajab, Far, and Etemadzadeh (2012), OL2S (oughtto L2 self) had the lowest coefficient with L2LEbut the highest coefficient with IPre (instrumentalityprevention). This might be largely because the participants in the present study chose to study Chinese in China of their own will, hardly influenced by their parents, peers, and/or others around them. It might also be because people around them did not have a great impact on their Chinese learning, as found in Cruz and $\mathrm{Al}$ Shabibi (2019). Concurrently, this finding further confirmed the proposition that ought-to self resembles the more external types of instrumental motives (Dörnyei \& Chan, 2013; Higgins, 1987). 
Meanwhile, the present study found that only the number of foreign languages learned was significantly positively related to IL2S (ideal L2 self) and Int (integrativeness), partially consistent with that in Humphreys and Spratt (2008). Moreover, this finding proved the belief that ideal self and integrative motivation are critically related to SL/FL learning (Dörnyei, 1994; Gardner, 1985; Rajab et al., 2012). In addition, the present study found female students had more positive perceptions of their ideal L2 selves. This might be because females tend to have a brighter image of the future and their ideal selves, which needs further research.

\section{Profiles of the participants'L2 motivation}

Statistical analyses revealed that the participants in the present study had great motivational intensity to study Chinese, held (fairly) positive images of their ideal and ought-to selves, had preferable attitudes toward their L2 learning experience, were highly instrumentally and integratively motivated, and had a high motivation of having an international posture, similar to that in other studies (Alshahrani, 2016; Chen, 2015; Csizér \& Luka'cs, 2010; Liu, 2017; O'Reilly, 2014; Wen, 2011; Winke, 2013).This might be because the respondents were immersed in the native language environment and most had the experience of learning more than one foreign language. As discussed in DeKeyser (2007), Hernández (2010), and Morreale (2011), the native language environment or the study-abroad context helps to motivate learners to study the target language and improve their proficiency in the language.

Moreover, though having a similar tendency to that of the whole sample, female respondents held significantly more favorable perceptions of their ideal selves than their male peers, partially supporting the result of 'gender role intensification' in Henry (2009, cited in Dörnyei \& Chan, 2013). Nevertheless, this needs to be researched further.

\section{Predictive effects of L2 motivation and demographic variables on Chinese proficiency}

Different from the finding that L2MSS components are closely related to SL/FL learning revealed in many studies (Cruz \& Al Shabibi, 2019; Csizér \& Luka'cs, 2010), regression analyses showed that when working alone, no L2MSS scale had a predictive effect on the students' Chinese proficiency in the present study. This could be largely attributed to the fact that the students' Chinese proficiency was measured by their self-ratings in the present study. The results might be different if students' Chinese proficiency was measured by a standardized Chinese proficiency test, which will be carefully designed in future research.

Of the measured demographic variables, LSC (length of stay in China) was found to powerfully predict students' proficiency in Chinese. This result further supported the finding in Martinsen (2008) and Hernández (2010) that the study-abroad context helps motivate learners to study the target language and improve their proficiency in the target language. Unexpectedly, hours spent using Chinese per day was not a predictor for proficiency in Chinese, nor was it significantly related to L2 motivation, unlike Liu's findings $(2017,2019)$. This might be because the students' L2 motivation was measured by the L2MSS questionnaire, different from Liu (2017, 2019) guided by Gardner's socio-educational model (1985), which is worth further research.

In regard to the interactive effect of L2MSS scales and demographic variables on proficiency in Chinese, regression analyses showed that LSC (length of stay in China) and gender were powerful positive predictors for the latter. This might be partially because gender was a distinguishing variable in some L2MSS scales, which interacted with LSC to affect students' proficiency in Chinese. Considering the relatively small sample size in the present research, this result needs to be confirmed in future research.

\section{Conclusion}

The present research explored L2 motivation, demographic variables, and Chinese proficiency among adult learners of Chinese as a second language. Analyses of the data revealed the following findings:

1) the L2MSS scales were significantly highly related to one another,

2) IL2S (ideal L2 self) and Int (integrativeness) were significantly positively related to the number of foreign languages learned, IL2S was also significantly correlated with gender, 
3) the whole sample, as well as male and female participants, made good or even great efforts to study Chinese, held (fairly) high perception of their ideal and ought-to selves, had positive attitudes toward their L2 learning experience, were highly instrumentally and integratively motivated, and had a great motivation of having an international posture,

4) female respondents held significantly more favorable perceptions of their ideal selves than their male peers, and

5) the L2MSS scales had no predictive effect or interactive effect with demographic variables on the students' Chinese proficiency. Nevertheless, length of stay in China and gender proved to be powerful positive predictors for the students' Chinese proficiency.

The L2MSS scales were found to be highly reliable and proved to be important dimensions of L2 motivation and play important roles in second/foreign language learning. That being said, it is necessary to continue to explore, understand, and enhance students' L2 motivation.

\section{Pedagogical Implications and Suggestions for Future Research}

The findings of the present research have several implications for SL/FL teaching and learning. On the one hand, it is necessary for teachers to be aware of the role of motivation in achieving learners' SL/FL learning goals (Cruz \& Al Shabibi, 2019). This can be done by sharing their own SL/FL learning experiences, guiding learners to imagine themselves as members of a globalized speech community while and after achieving their learning goals, encouraging learners to imagine what kind of person they want to be at present and in the future, and relate their learning of the SL/FL to their present and future selves. Teachers can also help to create favorable learning experiences for SL/FL learners. As discussed in Papi (2010), the L2 learning experience involves situation-specific motives like the curriculum, the L2 teacher, and the learning materials. Hence, a favorable learning experience can (greatly) increase learners' motivation to study the SL/FL (Papi, 2010). Teachers can help arouse powerful and vivid views of the successful L2 speakers to motivate a strong interest among their learners and design useful tasks to invoke such images (Taugchi et al., 2009). For example, Guilloteaux and Dörnyei (2008) investigated the relationship between 27 South Korean teachers' motivational teaching practice and their students' English learning motivation, which involved 40 ESL classrooms and more than 1,300 learners. Analyses of questionnaires and classroom observations revealed that the language teachers' motivational practice increased levels of the learners' motivated learning behavior as well as their motivational state. The researchers, thus, advised language instructors to raise their awareness of the importance of motivating learners and undertaking motivation-raising teaching practices. These findings were supported by subsequent research (Papi \& Abdollahzadeh, 2012) that examined the relationship between teachers' use of motivational strategies and students' motivated behavior in the EFL context of Iran. The study recruited 741 male learners of English from 26 secondary school classes taught by 17 teachers. The study showed that the teachers' motivational practice was significantly related to the students' motivated behavior and that the low-motivation group had stronger ought-to L2 selves.

On the other hand, learners can (be encouraged to) generate and/or enhance their vision of SL/FL learning, as discussed in Dörnyei (2008). This can be done by raising awareness, drawing on powerful role models and pinpointing the significance of the ideal L2 self to construct the ideal L2 self, strengthening the vision, and developing an action plan to realize the ideal L2 self (Dörnyei, 2008). For example, if learners want to become fluent L2speakers who are able to effectively interact with foreign friends, they should take advantage of available opportunities to engage themselves in oral interactions in the L2 (Dörnyei, 2009a). If learners want to become the person their parents expect them to be, they should be (greatly) motivated to study the SL/FL to receive their parents' praise and rewards (Higgins, 1987).

The present study not only examined L2 motivation profiles but also the predictive effects of L2 motivation on Chinese proficiency, as well as its interactive effects with demographic variables on Chinese proficiency among adult learners of Chinese as a SL, enriching the current literature on L2MSS that calls for more research on the issue and on learners of foreign languages other than English. Even so, similar to Cruz and Al Shabibi (2019), the present study also attests that much work is still needed on examining L2 motivation in relation to various factors such as the learning context and individual characteristics. As discussed in Dörnyei (2009a), a longitudinal study with mixed methods may be preferable for future research of an identical nature as there are many unmentioned factors (e.g., globalization and the complexities of the learners' psychological profile, etc.) 
that may influence the level of L2 motivation. For example, Gao, Zhao and Cheng's (2007) survey study of 2,278Chinese college students revealed a strong correlation between motivation types and self-identity changes. Future research can center on the relationship between the L2SSM and other factors such as selfidentity and learning strategy use (Ushioda, 2011; Ushioda \& Dörnyei, 2009; Xu, 2011). Moreover, as discussed in Dörnyei and Al-Hoorie (2017), the self-concept of learning English has somehow become a referent selfconcept of learning other languages. Nevertheless, the self-concept of learning a second, third, and nth language is different from that of learning English since the context is different. Consequently, learners' selfconcepts and motivation related to learning different FLs always deserve research, especially in relation to their individualistic and social contexts, as discussed in MacIntyre, Baker and Sparling (2017) and Henry (2017). As English has become a lingua franc around this world, it seems that people increasingly tend to regard the study of English as a self-evident part of education rather than as driven by an L2-specific motivational decision or see English-related motivation or self-image as the referent motivation or self-image (Dörnyei \& Al-Hoorie, 2017; Henry, 2017). Dörnyei (2009a) claimed that the interplay among language, agent, and environment in the language acquisition process highlights the need for further research in this area. Therefore, it will be interesting to explore differences and similarities in L2 motivation between learners of English as a SL/FL and those of learning SLs/FLs other than English. As discussed in Henry (2010), a strong English-related ideal self might interfere the learning of another foreign language, which deserves further research.

Finally, Waninge, Dörnyei, and de Bot's (2014) questionnaire study of 709 students together with classroom observations of four language learners over a period of two weeks showed that L2 motivation changed over time at an individual level as the context changed. The researchers thus suggested that L2 motivation be studied at different interacting time scales. This dynamic nature of L2 motivation was supported by Kim's (2006) study of 365 Korean EFL high school students, which showed that EFL motivation changed during time. Hence, it is important and necessary to conduct cross-sectional research to better understand how L2 motivation changes over time (Dörnyei, 2014).

\section{References}

Alshahrani, A. A. S. (2016). L2 motivational self system among Arab EFL learners: Saudi perspective. International Journal of Applied Linguistics \& English Literature, 5(5), 145-152. http://dx.doi.org/10.7575/aiac. ijalel.v.5n.5p.145

Boo, Z., Dörnyei, Z., \& Ryan, S. (2015). L2 motivation research 2005-2014: Understanding a publication surge and a changing landscape. System, 55(1), 145-157. http://dx.doi.org/10.1016/j.system.2015.10.006

Chen, Y. (2015). An empirical study sophomores' L2 motivational self system [Unpublished MA thesis]. North China University of Technology.

Cohen, J. (1988). Statistical power analysis for the behavioral sciences ( $2^{\text {nd }}$ ed.). Lawrence Erlbaum Associates.

Cruz, S., \& Al Shabibi, N. (2019). The L2 motivational self: A case of college students at Ibra College of Technology. TESL Reporter, 52(1), 30-51. http://dx.doi.org/10.1002/tesq.129

Csizér, K., \& Dörnyei, Z. (2005). The internal structure of language learning motivation and its relationship with language choice and learning effort. The Modern Language Journal, 89(1), 19-36. https://doi.org/10.1111/ j.0026-7902.2005.00263.x

Csize'r, K., \& Dörnyei, Z. (2005). Language learners' motivational profiles and their motivated learning behavior. Language Learning, 55(4), 613-659. https://doi.org/10.1111/j.0023-8333.2005.00319.x

Csizér, K., \& Kormos, J. (2008). The relationship of intercultural contact and language learning motivation among Hungarian students of English and German. Journal of Multilingual and Multicultural Development, 29(1), 30-48. https://doi.org/10.2167/jmmd557.0

Csize'r, K., \& Luka'cs, G. (2010). The comparative analysis of motivation, attitudes and selves: The case of English and German in Hungary. System, 38(1), 1-13. https://doi.org/10.1016/j.system.2009.12.001

DeKeyser, R. (2007). Study abroad as foreign language practice. In R. DeKeyser (Ed.), Practice in a second language: Perspectives from applied linguistics and cognitive psychology (pp. 208-226). CUP.

Dörnyei, Z. (2005). The psychology of the language learner: Individual differences in second language acquisition. Lawrence Erlbaum Associates, Inc. Publishers.

Dörnyei, Z. (2008). New ways of motivating foreign language learners: Generating vision. Links, 38, 3-4.

Dörnyei, Z. (2009a). Individual differences: Interplay of learner characteristics and learning environment. 
Language Learning, 59(suppl. 1), 230-248. https://doi.org/10.1111/j.1467-9922.2009.00542.x

Dörnyei, Z. (2009b). The L2 motivational self system. In Z. Dörnyei \& E. Ushioda (Eds.), Motivation, language identity and the L2 self (pp. 9-42). Multilingual Matters.

Dörnyei, Z. (2014). Researching complex dynamic systems: Modelling in the language classroom. Language Teaching, 47(1), 80-91. http://dx.doi.org/10.1017/S0261444811000516

Dörnyei, Z., \& Chan, L. (2013). Motivation and vision: An analysis of future L2 self images, sensory styles, and imagery capacity across two target languages. Language Learning, 66(3), 437-462. http://dx.doi.org/10.1111/ lang.12005

Dörnyei, Z., \& Csizér, K. (2006).Motivation, language attitudes and globalization: A Hungarian perspective (vol. 18). Multilingual Matters.

Dörnyei, Z., \& Al-Hoorie, A. H. (2017). The motivational foundation of learning languages other than global English: Theoretical issues and research directions. The Modern Language Journal, 101(3), 455-468. http:// dx.doi.org/10.1111/modl.12408

Gao, Y., Zhao, Y., \& Cheng, Y. (2007). Relationship between English learning motivation types and self-identity changes among Chinese students. TESOL Quarterly, 4O(1), 133-156. https://doi.org/10.1002/j.1545-7249.2007. tb00043.x

Gardner, R. C. (1985). Social psychology and second language learning: The role of attitudes and motivation. Edward Arnold.

Gardner, R. C., \& Lambert, W. E. (1972). Attitudes and motivation in second language learning. Newbury House.

Gardner, R. C., \& MacIntyre, P. D. (1992). Integrative motivation, induced anxiety, and language learning in a controlled environment. Studies in Second Language Acquisition, 14, 197-214. https://doi.org/10.1017/ S0272263100010822

Grant, S., Huang, H., \& Pasfield-Neofitou, S. (2018). Engagement in second life: Language anxiety and motivation. In S. Gregory \& D. Wood (Eds.), Authentic virtual world education (pp. 95-115). Springer.

Guilloteaux, M. J., \& Dörnyei, Z. (2008). Motivating language learners: A classroom-oriented investigation of the effects of motivational strategies on student motivation. TESOL Quarterly, 42(1), 55-77.

Henry, A. (2010). Contexts of possibility in simultaneous language learning: Using the L2 motivational self system to assess the impact of global English. Journal of Multilingual and Multicultural Development, 31, 149162. https://doi.org/10.1080/01434630903471439

Henry, A. (2017). L2 motivation and multilingual identities. Modern Language Journal, 101, 548-565. https://doi. org/10.1111/modl.12412

Hernández, T. A. (2010). The relationship among motivation, interaction, and the development of second language oral proficiency in a study-abroad context. The Modern Language Journal, 94(4), 600-617. https:// doi.org/10.1111/j.1540-4781.2010.01053.x

Higgins, E.T. (1987) Self-discrepancy: A theory relating self and affect. Psychological Review, 94, 319-340.

Humphreys, G., \& Spratt, M. (2008). Many languages, many motivations: A study of Hong Kong students' motivation to learn different target languages. System, 36(2), 313-335. https://doi.org/10.1016/j. system.2007.09.010

Islam, M., Lamb, M., \& Chambers, G. (2013). The L2 motivational self-system and national interest: A Pakistani perspective. System, 41(2), 231-244. https://doi.org/10.1016/j.system.2013.01.025

Kim, T.Y. (2009b). The dynamics of L2 self and L2 learning motivation: A qualitative case study of Korean ESL students. English Teaching, 64(3), 133-154.

Kim, T.-Y. (2006). Motivation and attitudes toward foreign language learning as socio-politically mediated constructs: The case of Korean high school students. The Journal of Asia TEFL, 3(2), 165-192. https://www. researchgate.net/publication/312454651

Kim, T. \& Kim, Y. (2014). EFL students' L2 motivational self system and self-regulation: Focusing on elementary and junior high school students in Korea. In K. Csizér \& M. Magid (Eds.), The impact of self-concept on language learning (pp. 87-107). Multilingual Matters.

Kormos, J., \& Csizer, K. (2014). The interaction of motivation, self-regulatory strategies, and autonomous learning behavior in different learner groups. TESOL Quarterly, 48(2), 275- 299. http://dx.doi.org/10.1002/ tesq. 129

Liu, F. (2010). A study on Chinese EFL learners' motivation from the perspective of L2MSS [Unpublished doctoral dissertation]. Shanghai International Studies University.

Liu, M. (2016). Study abroad and university students' whole-person development: A case study. Tsinghua University Press.

Liu, M. (2017). Motivation, motivation intensity, use of Chinese and self-rated proficiency in Chinese. College 
Student Journal, 51(1), 63-76.

Liu, M. (2019). Understanding motivation for learning German among Chinese college students: Comparing inChina and study-abroad contexts. Creative Education, 10, 163-177.

MacIntyre, P. D., Baker, S. C., \& Sparling, H. (2017). Heritage passions, heritage convictions and the rooted L2 self: Music and Gaelic language learning in Cape Breton, Nova Scotia. Modern Language Journal, 101, 501516. https://doi.org/10.1111/modl.12417

Markus, H., \& Nurius, P. (1986). Possible selves. American Psychologist, 41(9), 954-969.

Martinsen, R. A. (2008). Short-term study abroad: predicting changes in oral skills. Foreign Language Annals, 43(3), 504-530. https://doi.org/10.1111/j.1944-9720.2010.01095.x

Morreale, S. G. S. (2011). The relationship between study abroad and motivation, attitude and anxiety in university students learning a foreign language [Unpublished doctoral dissertation]. ProQuest Dissertations Publishing.

O'Reilly, E. N. (2014). Correlations among perceived autonomy support, intrinsic motivation, and learning outcomes in an intensive foreign language program. Theory and Practice in Language Studies, 4(7), 13131318. http://dx.doi.org/10.4304/tpls.4.7.1313-1318

Papi, M. (2010). The L2 motivational self-system, L2 anxiety, and motivated behavior: A structural equation modelling approach. System, 38, 467-479. https://doi.org/10.1016/j.system.2010.06.011

Papi, M., \& Abdollahzadeh, E. (2012). Teacher motivational practice, student motivation, and possible L2 selves: An examination in the Iranian EFL context. Language Learning, 62(2), 571-594. http://dx.doi.org/10.1111/ j.1467-9922.2011.00632.x

Pawlak, M. (2016a). Investigating language learning motivation from an ideal language-self perspective: The case of English majors in Poland. In G. Dagmara, P. Zakrajewski \& M. Pawlak (Eds.), Researching second language learning and teaching from a psycholinguistic perspective (pp.53-69). Springer International Publishing.

Pawlak, M. (2016b). Another look at the L2 motivational self system of Polish students majoring in English: Insights from interview data. Theory and Practice of Second Language Acquisition, 2(2), 9-26.

Rajab, A., Far, H. R., \& Etemadzadeh, A. (2012). The relationship between L2 motivational self system and L2 learning among TESL students in Iran. Procedia-Social and Behavioral Sciences, 66, 419-424. https://doi. org/10.1016/j.sbspro.2012.11.285

Ryan, S. (2009). Self and identity in L2 motivation in Japan: The ideal L2 self and Japanese learners of English. In Z. Dörnyei \& E. Ushioda (Eds.), Motivation, language identity and the L2 self (pp. 120-143). Multilingual Matters.

Taguchi, T., Magid, M., \& Papi, M. (2009). The L2 motivational self system among Japanese, Chinese, and Iranian learners of English: A comparative study. In Z. Dörnyei \& E. Ushioda (Eds.), Motivation, language identity and the L2 self (pp. 144-163). Multilingual Matters.

Tremblay, P. F., \& Gardner, R. C. (1995). Expanding the motivation construct in language learning. The Modern Language Journal, 79(4), 505-518. https://doi.org/10.1111/j.1540-4781.1995.tb05451.x

Ushioda, E. (2011). Language learning motivation, self and identity: current theoretical perspectives. Computer Assisted Language Learning, 24(3), 199-210. https://doi.org/10.1080/09588221.2010.538701

Ushioda, E., \& Dörnyei, Z. (2009). Motivation, language identities and the L2 self: A theoretical overview. In Z. Dörnyei \& E. Ushioda (Eds.), Motivation, language identity and the L2 self (pp. 1-8). Multilingual Matters.

Waninge, F., Dörnyei, Z., \& de Bot, K. (2014). Motivational dynamics in language learning: Change, stability, and context. The Modern Language Journal, 98(3), 704-723. http://dx.doi.org/10.1111/j.1540-4781.2014.12118.x

Wen, X. (2011). Chinese language learning motivation: A comparative study of heritage and non-heritage learners. Heritage Language Journal, 8(3), 41-66.

Winke, P. (2013). An investigation into second language aptitude for advanced Chinese language learning. The Modern Language Journal, 97(1), 109-130. http://dx.doi.org/10.1111/j.1540-4781.2013.01428.x

$\mathrm{Xu}, \mathrm{X}$. (2011). The relationship between language learning motivation and the choice of language learning strategies among Chinese graduates. International Journal of English Linguistics, 1(2), 203-212.

Yashima, T. (2009). International posture and the ideal L2 self in the Japanese EFL context. In Z. Dörnyei \& E. Ushioda (Eds.), Motivation, language identity and the L2 self (pp. 144-163). Multilingual Matters. 